\title{
Pelaksanaan Sistem Zonasi dalam Penerimaan Peserta Didik Baru (PPDB) Tahun Ajaran 2019/2020 di Kota Padang
}

\author{
Ayu Azhari, Suryanef \\ Program Studi Pendidikan Pancasila dan Kewarganegaraan \\ Universitas Negeri Padang \\ E-mail: ayuazhari2408@gmail.com
}

\section{ABSTRAK}

Penelitian ini dilatarbelakangi oleh munculnya sistem zonasi untuk mengatasi persoalan ketimpangan kualitas pendidikan. Tujuan penelitian ini yaitu untuk mendeskripsikan pelaksanaan sistem zonasi sehingga terjadinya pemerataan pendidikan. Penelitian ini dilaksanakan di Sekolah Menengah Pertama Kota Padang. Penelitian ini menggunakan penelitian kualitatifmetode deskriptif dengan informan penelitian yang terdiri dari Kepala UPTD Dapodik, Kepala Sekolah, panitia pelaksana PPDB. Teknik pengumpulan data yang digunakan berupa wawancara dan studi dokumentasi. Jenis data dan sumber data menggunakan data primer dan data sekunder. Hasil penelitian menunjukkan dari segi komunikasi belum berjalan dengan baik karena sosialisasi yang diadakan oleh pihak terkait belum menjangkau orang tua dan calon peserta didik. Kemudian sumber daya manusia, sarana dan prasarana serta pendanaan sudah berjalan dengan baik. Disposisi sudah berjalan dengan baik karena pihak pelaksana sudah serius dalam melaksanakan kebijakan. Begitupun dengan struktur birokrasi yang sudah sesuai dengan tugas masing-masing dalam pelaksanaan kebijakan zonasi. Selain itu hasil penelitian menunjukkan bahwa pelaksanaan PPDB sistem zonasi telah berhasil dalam upaya pemerataan akses dan mutu pendidikan. Dari sisi jarak rumah siswa dengan sekolah sudah dekat karena menggunakan zonasi sekolah SD asal. Dari sisi mutu siswa juga telah menyebar diberbagai sekolah dengan adanya nilai maksimum dan minimum dalam suatu rombongan belajar di sekolah.

Kata Kunci: sistem zonasi, PPDB, Kota Padang

\section{ABSTRACT}

This research is backed by the emergence of zoning system to overcome the inequality of eduacation quality. The purpose of this research is to describe the implementation of zoning system so that the education. This research was conducted on junior high school Padang City, uses qualitative and decriptive methods with informers consisting of the head of UPTD Dapodik, principal, managing committe of PPDB. The data collection techniques uses are interviews and documentation studies. Data types and data sources use primary data and secondary data. The validity test of data is done by triangulating the source and triangulation methods. Analysis of the data used is data reduction, data presentation and withdrawal of conclusion and verified. The results show, in communication has not gone well because the socialization held by the associated has not reached the parents and prosprective new student. 
Resources such as human resources, good advice and infrastructure is already running well. The disposition has been done well because the executor is serious in implementing the policies. The structure of the bureaucracy is already in accordance with each task in the implementation of zoning policy. in addition, the research results show implementation of $P P D B$ zoning system has succeeded in the effort of equalization access and quality of education. From the distance of the home of the student and the school is close by using the zones of the elementary school. From the quality of student has also spread in various schools in the presence of maximum and minimum values in study group of the school.

Keywords : zoning system, PPDB, Kota Padang

This work is licensed under the Creative Commons Attribution-ShareAlike 4.0 International License. (2019 by author.

\section{PENDAHULUAN}

Pelaksanaan sistem zonasi merupakan suatu kebijakan baru yang tertuang dalam penerimaan peserta didik baru. Sistem zonasi pendidikan dilaksanakan untuk mengatasi ketimpangan kualitas pendidikan. Adanya ketimpangan kualitas pendidikan di Indonesia terlihat dari disparitas taraf pendidikan antar kelompok masyarakat seperti perbedaan pendidikan antar wilayah perkotaan dan perdesaan, serta perbedaan pendidikan antar penduduk kaya dan miskin. Masalah ketimpangan kualitas pendidikan dapat dilihat dari kualitas dan distribusi guru yang belum merata, infrastruktur yang rusak dan tidak layak, yang bermuara pada mutu pendidikan yang belum tercapai. Pelaksanaan sistem ini diharapkan dapat memeratakan kualitas pendidikan dan memberikan kesejahteraan bagi semua warga dalam mendapatkan pendidikan.

Penelitian mengenai pelaksanaan sistem zonasi di Kota Padang penting dan menarik dikarenakan beberapa alasan. Pertama, pelaksanaan sistem zonasi ini bertujuan untuk melaksanakan penerimaan peserta didik baru yang objektif, transparan, tanpa diskriminasi, dan berkeadilan dalam rangka meningkatkan akses layanan dan mutu pendidikan. Kebijakan pelaksanaan sistem zonasi ini pada prinsipnya agar dapat mendekatkan layanan pendidikan ke masyarakat dan memeratakan mutu pendidikan. Kedua, pelaksanaan sistem zonasi dimaksudkan untuk pemerataan kualitas pendidikan sehingga dapat menghilangkan dikotomi sekolah unggul dan non unggul. Dengan adanya zonasi pendidikan akan menjadikan semua sekolah memiliki kedudukan, peran, fungsi yang sama dalam melayani setiap peserta didik.

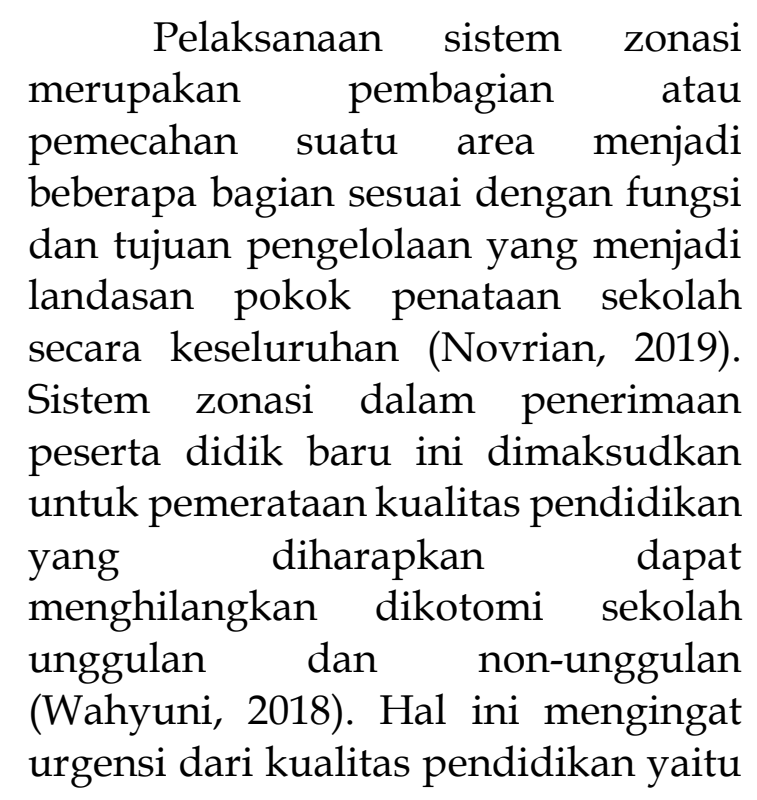


pemerataan akses dan pemerataan mutu pendidikan, maka pemerintah menjalankan kebijakan zonasi pendidikan (Novrian, 2019). Pelaksanaan sistem zonasi dapat menguntungkan calon peserta didik yang tinggal berdekatan dengan sekolah yang artinya dapat mengurangi waktu tempuh ke sekolah (Andina, 2017).

Penelitian terkait pelaksanaan sistem zonasi di Kota Padang ini dilakukan karena terlihat kesenjangan pendidikan dari sekolah yang berada didaerah perkotaan dan perdesaan serta perbedaan sekolah unggulan dan non-unggulan. Untuk daerah perkotaan diberikan kemudahan dalam akses transportasi seperti daerah Imam Bonjol, Lolong, Lubuk Buaya. Sedangkan daerah perdesaan seperti daerah Bungus kurang menjadi perhatian pemerintah karena lokasinya yang berada jauh dari pusat kota bahkan transportasi kesana pun sulit. Agar sekolah yang berada di daerah perdesaan dapat terisi maka dengan adanya sistem zonasi ini harapannya siswa dapat sekolah dekat dengan tempat tinggalnya. Selain itu masih adanya pro dan kontra maupun aduan pada masyarakat terhadap pelaksanaan sistem zonasi di Kota Padang, seperti belum meratanya kualitas setiap sekolah, adanya bangku kosong di sejumlah sekolah.

Penelitian terdahulu yaitu penelitian Elga Andina (2017) tentang sistem zonasi dan dampak psikososial bagi perserta didik. Hasil penelitian menunjukkan bahwa dengan adanya sistem zonasi ini dapat menghambat prestasi siswa karena kondisi kelas yang heterogen yang menjadikan standar kelas menjadi rendah. Selanjutnya penelitian Dinar Wahyuni
(2018) tentang pro dan kontra sistem zonasi penerimaan peserta didik baru tahun ajaran 2017/2018. Hasil penelitian menunjukkan bahwa ada beberapa hal yang masih menjadi perdebatan seperti jark tempat tiggal, perbedaan penafsiran peraturan siberbagai daerah, dan penyalahgunaan SKTM. Selanjutnya penelitian oleh Novrian Satria (2019) tentang implementasi PPD zonasi dalam upaya pemerataan akses dan mutu pendidikan. Hasil penelitian menunjukkan bahwa pelaksanaan PPDB zonasi di Sulawesi Tengah telah berhasil dalam upaya memeratakan akses dan mutu pendidikan.

\section{METODE PENELITIAN}

Metode penelitian yang digunakan adalah kualitatif. Lokasi penelitian yaitu di SMP Negeri 7 Padang dan SMP Negeri 43 Padang. Proses pengumpulan data dilakukan dengan mengggunakan beberapa cara. Pertama, mengadakan wawancara terstruktur dan wawancara tidak terstruktur yang dilakukan dengan Kepala UPTD Dapodik, Kepala Sekolah, panitia pelaksana PPDB. Kedua, penulis mengumpulkan data melalui studi dokumentasi yaitu mengumpulkan dokumen terkait yang berkaitan dengan pelaksanaan sistem zonasi di Kota Padang seperti Petunjuk Teknis yang tertuang dalam Peraturan Walikota Kota Padang. Teknik analisis data yang digunakan melalui tiga tahap antara lain reduksi data yaitu merangkum hasil wawancara dengan para informan terkait hal-hal yang dianggap penting mengenai pelaksanaan sistem zonasi, selanjutnya data yang didapatkan dari wawancara serta studi dokumentasi disajikan lalu dilakukan penarikan kesimpulan. 


\section{HASIL DAN PEMBAHASAN}

\section{Pelaksanaan Sistem Zonasi di Kota Padang}

Pelaksanaan sistem zonasi di Kota Padang telah dilaksanakan sejak tahun 2017 dengan dilandasi Peraturan Menteri Pendidikan Dan Kebudayaan No 20 Tahun 2019 dengan petunjuk teknis di Kota Padang yaitu Peraturan Walikota No. 32 tahun 2019. Peneliti menganalisa berdasarkan Teori Edward III yang terdiri dari empat komponen yaitu komunikasi, sumber daya, disposisi, dan struktur birokrasi, yang dapat dilihat di tabel berikut:

\section{$\underline{\text { Tabel } 1}$}

Pelaksanaan Sistem Zonasi di Kota Padang (olahan peneliti, 2019)

\begin{tabular}{|c|c|c|c|}
\hline $\begin{array}{l}\mathbf{N} \\
\mathbf{0}\end{array}$ & Aspek & Deskripsi & Capaian \\
\hline 1 & $\begin{array}{l}\text { Komunika } \\
\text { si }\end{array}$ & $\begin{array}{l}\text { Komunikas } \\
\mathrm{i} \quad \text { yaitu } \\
\text { adanya } \\
\text { penyampai } \\
\text { an } \\
\text { informasi } \\
\text { terkait } \\
\text { proses } \\
\text { pelaksanaa } \\
\text { n suatu } \\
\text { kebijakan. }\end{array}$ & $\begin{array}{l}\text { belum } \\
\text { optimal, } \\
\text { dikarenakan } \\
\text { sosialisasi } \\
\text { yang diadakan } \\
\text { oleh pihak } \\
\text { terkait belum } \\
\text { menjangkau } \\
\text { orang tua dan } \\
\text { calon peserta } \\
\text { didik baru. }\end{array}$ \\
\hline 2 & $\begin{array}{l}\text { Sumber } \\
\text { daya }\end{array}$ & $\begin{array}{l}\text { Sumber } \\
\text { daya } \\
\text { terbagi atas } \\
\text { sumber } \\
\text { daya } \\
\text { manusia, } \\
\text { sarana dan } \\
\text { prasarana, } \\
\text { serta } \\
\text { pendanaan } \\
\text { dalam } \\
\text { pelaksanaa } \\
\text { n } \\
\text { kebijakan. }\end{array}$ & $\begin{array}{l}\text { sudah baik, } \\
\text { baik dari segi } \\
\text { sumber daya } \\
\text { manusia, } \\
\text { sumber daya } \\
\text { sarana dan } \\
\text { prasarana dan } \\
\text { sumber daya } \\
\text { finansial } \\
\text { dalam } \\
\text { pelaksanaanny } \\
\text { a. }\end{array}$ \\
\hline
\end{tabular}

Volume 2 No. 52019

\begin{tabular}{|c|c|c|c|}
\hline 3 & Disposisi & $\begin{array}{l}\text { Disposisi } \\
\text { merupakan } \\
\text { sikap dan } \\
\text { keseriusan } \\
\text { dari pihak } \\
\text { pelasana } \\
\text { kebijakan. }\end{array}$ & $\begin{array}{l}\text { sudah baik, } \\
\text { dikarenakan } \\
\text { pihak } \\
\text { pelaksana } \\
\text { sudah mampu } \\
\text { serius dalam } \\
\text { melaksanakan } \\
\text { kebijakan } \\
\text { sistem zonasi } \\
\text { ini. }\end{array}$ \\
\hline 4 & $\begin{array}{l}\text { Struktur } \\
\text { Birokrasi }\end{array}$ & $\begin{array}{l}\text { Struktur } \\
\text { birokrasi } \\
\text { yaitu } \\
\text { tersedianya } \\
\text { struktur } \\
\text { organisasi } \\
\text { khusus } \\
\text { yang } \\
\text { bekerja } \\
\text { sesuai } \\
\text { pelaksanaa } \\
\text { n } \\
\text { kebijakan. }\end{array}$ & $\begin{array}{l}\text { sudah baik, } \\
\text { dikarenakan } \\
\text { dari pihak } \\
\text { dinas } \\
\text { pendidikan } \\
\text { Kota Padang } \\
\text { sudah } \\
\text { memiliki } \\
\text { struktur } \\
\text { birokrasi } \\
\text { untuk } \\
\text { mengatur } \\
\text { pelaksanaan } \\
\text { sistem zonasi. }\end{array}$ \\
\hline
\end{tabular}

Berdasarkan empat poin

tersebut, poin pertama adalah komunikasi. Komunikasi berdasarkan model implementasi George C. Edward dalam Agustino (2012: 149) merupakan salah satu variabel yang dapat menentukan keberhasilan tujuan dari sebuah pelaksanaan kebijakan. Komunikasi dalam pelaksanaan sistem zonasi berkaitan dengan sosialisasi untuk sasaran kebijakan. Dari data yang didapatkan komunikasi dalam pelaksanaan sistem zonasi belum optimal yakni belum sampainya sosialisasi kepada orang tua dan calon peserta didik dengan baik. Pihak terkait yaitu bagian tim sosialisasi yang disusun khusus oleh Dinas Pendidikan Kota Padang yang bertugas untuk mensosialisasikan pelaksanaan sistem zonasi kepada kepala sekolah, koordinator wilayah, media-media seperti televisi, radio maupun media cetak yang 
dilaksanakan dua bulan sebelum pelaksanaan Penerimaan Peserta Didik Baru.

Selanjutnya dari pihak sekolah juga telah mensosialisasikan ini kepada siswa dan orang tua siswa melalui brosur dan panduan pelaksanaan PPDB zonasi pada papan pengumuman dan tempat strategis yang dapat dilihat oleh masyarakat. Hal ini sesuai dengan pasal 4 bagian pengumuman Peraturan Walikota Padang No 32 tahun 2019 bahwa persyaratan, tanggal pendaftaran, jalur pendaftaran serta jumlah daya tampung telah diumumkan melalui papan pengumuman sekolah seperti brosur atau buku panduan yang dapat dilihat oleh masyarakat luas.

Kedua, sumber daya dalam Mulyadi (2016: 68) merupakan hal yang penting dalam suatu pelaksanaan kebijakan, baik sumber daya manusia maupun sumber daya non manusia. Sumber daya yaitu sumber daya manusia yang dilihat dari kualifikasi dan kuantitas pelaksana penerimaan peserta didik baru dari Dinas Pendidikan Kota Padang dan panitia di sekolah sudah memadai. Sedangkan dari segi sarana dan prasarana bagi setiap sekolah yang melaksanakan sistem zonasi belum merata. Masih banyaknya sekolah yang berbeda dari segi sarana dan prasarananya. Hal inilah yang diupayakan oleh Pemerintah Kota Padang untuk menyamakan semua sekolah baik dari segi siswa maupun dari kualitasnya agar terciptanya pemerataan mutu pendidikan. Selanjutnya untuk sumber daya finansial dalam pelaksanaan sudah terlaksana dengan baik yang bersumber dari Anggaran Pendapatan Belanja Daerah (APBD) Kota Padang dan pihak sekolah dari Dana Bantuan Operasional Sekolah (BOS). Hal ini sudah sesuai dengan pasal 28 Peraturan Walikota Padang No 31 tahun 2019 yaitu biaya dalam pelaksanaan PPDB dan pendataan ulang pada sekolah dibebankan pada Bantuan Operasional Sekolah (BOS) dan tanpa memungut biaya pendaftaran pada siswa dan orang tua siswa.

Ketiga, disposisi dalam Mulyadi (2016: 70) merupakan kemauan, dan kecendrungan sikap para pelaksana kebijakan secara sungguh-sungguh sehingga dapat mencapai tujuan pelaksanaa kebijakan. Dari segi disposisi dari pihak pelaksana sudah melakukan tugasnya dengan baik dalam pelaksanan sistem zonasi dalam penerimaan peserta didik baru sesuai dengan Peraturam Walikota Kota Padang. Namun dari orang tua masih ditemui complain dalam pelaksanaan kebijakan sistem zonasi ini. Adanya orang tua yang merasa bahwa kebijakan ini membatasi mereka dalam memilih sekolah. Disposisi merupakan sikap, komitmen, dan keseriusan dalam melaksanakan suatu kebijakan.

Keempat, struktur birokrasi dalam Mulyadi (2016: 72) yaitu berhubungan dengan Standard 
Volume 2 No. 52019

Operating Procedur (SOP) atau pedoman dalam pelaksanaan kebijakan yang telah dibagi sesuai keahlian masing-masing. Dalam hal ini struktur birokrasi ditunjuk oleh Ketua Pelaksana PPDB zonasi sesuai dengan bidang dan keahlian masing-masing.

Selain empat poin di atas, pelaksanaan sistem zonasi di Kota Padang dilaksanakan berdasarkan zona sekolah asal seperti pada gambar dibawah ini :

\section{Gambar 1}

Proses Pembentukan Zonasi (Sumber : PSB.diknaspadang.id)

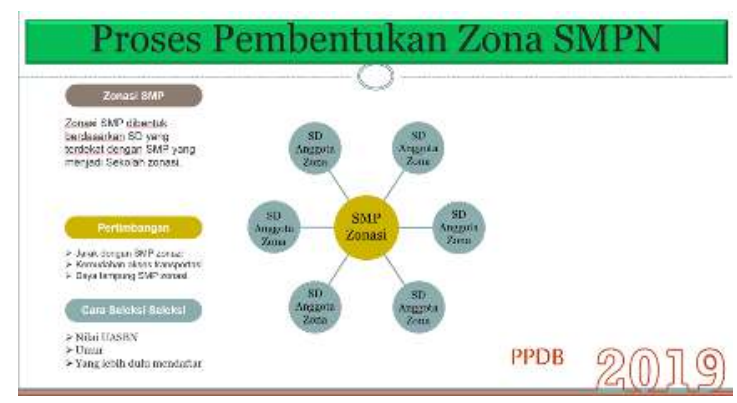

Gambar diatas menunjukkan bahwa dalam PPDB zonasi di Kota Padang dilakukan berdasarkan zona sekolah asal yang sesuai dengan Peraturan Walikota Padang pasal 7 ayat (4). Sistem zonasi ditetapkan dengan zona sekolah asal karena untuk zona tempat tinggal sulit untuk diukur jaraknya dan tidak meratanya keberadaan sekolah. Setiap sekolah yang dituju untuk mendaftar telah ditentukan SD anggota zona yang berhak mendaftar sesuai dengan zonasi tergantung dari jumlah rombongan belajar yang diterima di sekolah yang sistem zonasi bersangkutan. Meskipun menggunakan zona sekolah asal. Namun pada prinsipnya hal ini tetap mendekatkan peserta didik dari rumah ke sekolah. Hal ini membuktikan dari segi jarak pelaksanaan sistem zonasi telah berhasil mendekatkan siswa dari rumahnya.

Selain itu dalam pelaksanaan sistem zonasi telah menerima siswa dalam suatu sekolah dengan nilai maksimum dan nilai minimum. Pelaksanaan pendaftaran dalam menerima peserta didik dari semua kalangan dan terlihat sebaran peserta didik sudah merata dilihat dari nilai UASBN. Hal ini sesuai dengan pasal 24 dalam Peraturan Walikota Padang bahwa untuk jalur zonasi dilakukan berdasarkan nilai UASBN dengan prioritas zonasi. Dari data yang terdapat dalam hasil penelitian terlihat bahwa pemerataan kualitas pendidikan dari segi persebaran siswa sudah merata, tidak ada sekolah yang diunggulkan dengan siswa yang memiliki nilai tinggi. Di setiap sekolah ada yang menerima siswa yang mempunyai nilai maksimal dan mempunyai nilai minimal sehingga kondisi siswanya heterogen sehingga tidak membeda-bedakan antara satu sekolah dengan sekolah yang lain.

\section{SIMPULAN}

Pelaksanaan sistem zonasi dalam penerimaan peserta didik baru di Kota Padang tahun ajarana 2019/2020 secara keseluruhan dari segi komunikasi, sumber daya, disposisi, dan struktur birokrasi sudah baik karena sudah sesuai dengan standar pelaksanaan sistem zonasi meskipun ada beberapa hal yang belum dilaksanakan seperti belum optimal sosialisasi yang belum diterima oleh orang tua dan calon peserta didik. Selain itu secara umum pelaksanaan PPDB sistem zonasi telah 
berhasil dalam upaya pemerataan akses dan mutu pendidikan. Sebaran siswa dari sisi jarak sudah mendekat kerumah siswa karena menggunakan zonasi sekolah SD asal dan dari sisi mutu siswa juga telah menyebar diberbagai sekolah sehingga tidak ada lagi sekolah unggulan dan non unggulan.

\section{DAFTAR PUSTAKA}

Agustino, Leo. 2012. Dasar-dasar Kebijakan Publik. Bandung: Alfabeta.

Andina, Elga. 2017. Sistem Zonasi dan Dampak Psikososial Bagi Peserta Didik. Pusat Penelitian. Bidang keahlian DPR RI. Vol IX, No 14/II.

Mulyadi, D. 2016. Studi Kebijakan Publik dan Pelayanan Publik. Bandung: Alfabeta.

Peraturan Walikota Padang No 32 tahun 2019 tentang Penerimaan Peserta Didik Baru.

Satria, Novrian Perdana. 2019. Implementasi PPDB Zonasi dalam Upaya Pemerataan Akses dan Mutu Pendidikan. Jurnal Pendidikan Glaser. Vol. 3. No. 1.

Wahyuni, Dinar. 2018. Pro Kontra Sistem Zonasi Penerimaan Peserta Didik Baru Tahun Ajaran 2018/2019. Pusat Penelitian. Bidang Keahlian DPR RI. Vol X, No 14/II. 